\title{
Novel Coronavirus Disease (COVID-19) in the Northern African Countries: Perspectives and Data Update in the First Three Months
}

\author{
Mohamed Lounis ${ }^{1 *}$ (1) \\ ${ }^{1}$ University of Djelfa, ALGERIA \\ *Corresponding Author: lounisvet@gmail.com \\ Citation: Lounis M. Novel Coronavirus Disease (COVID-19) in the Northern African Countries: Perspectives and Data Update in the First \\ Three Months. Journal of Contemporary Studies in Epidemiology and Public Health. 2020;1(1):ep20006. \\ https://doi.org/10.30935/jconseph/8487
}

\begin{abstract}
The novel Coronavirus respiratory disease 2019 (COVID-19) has not stopped expanding and impressing the world since it started in Wuhan (China) on December 2019. The first case in Africa was reported in Egypt on February 14th, 2020. Since then, the disease has spread in all African countries and with the high prevalences in the Northern region including Egypt, Algeria, Tunisia and Morocco. The objective of this review is to describe the evolution of this disease in these countries and the measures implemented by their authorities to limit the spread of the virus using available data in the scientific databases (Pub med and Google scholar) and the specialized COVID-19 sites (John Hopkins Institute and our data in the world). We described that the North African countries were and still be affected and efforts are ongoing to control this pandemic disease.
\end{abstract}

Keywords: COVID-19, coronavirus, pandemic, North Africa

Received: 30 Jun. 2020 • Accepted: 31 Jul. 2020

\section{INTRODUCTION}

The novel coronavirus disease 2019 (COVID-19) is spreading in the world like wild fire [1]. Detected first in Wuhan, China, this respiratory illness has provoked a real confusion in the world. With an exponential transmission, the COVID-19 has afflicted more than 4 millions persons leaving til now more than 300,000 deaths [2].

The Northern African region (Morocco, Algeria, Tunisia, Libya and Egypt) as all countries and regions in the world has not escaped this disease [3]. Even the advent of the infection was delayed, by comparison with European countries and the United States, the first case in Africa was reported in this region on February $14^{\text {th }}$ in Egypt [3]. Since then, the other countries (Algeria, Morocco, Tunisia and lately Libya) reported their first cases and the number has steadily increased reporting the highest values in the African continent.

The current review was conducted to describe the evolution of the COVID-19 in the North African region, the current data and the means implemented in the fighting against this devastating disease. Due to the political instability and the low number of reported cases, Libya was excluded from this study. Data were collected from available publications concerning this disease in the four countries. The number of cases, deaths and laboratory tests was obtained from the Johns Hopkins Institute and Our data in world sites.

\section{Healthcare System}

Before the occurrence of COVID-19 the health systems of these countries were devastated and evidently weak [3] with a lack of adequate diagnostic facilities, and hospitals with no proper resources to handle infectious diseases. However, a wide difference existed between the four countries in matter of hospital beds, doctors and nurses and midwives per 1000 inhabitants (Table 1) [5]. Also, if Algeria had been listed among the less prepared countries to respond to health crisis of global importance by the Global Health Security Index in comparison to the other countries [4], it was considered with Egypt (and South Africa) the ones with the highest capacity to respond to outbreaks in Africa by a recent modeling study [6].

\section{Origin of Dirst Cases}

Egypt was the first North African country (and in all Africa) affected by COVID-19. It reported its first case on February $14^{\text {th }}, 2020$ [3]. On February $25^{\text {th }}$, Algeria reported the first case in the south department of Ouargla [7]. Later, on March $2^{\text {nd }}$, Morocco and Tunisia reported their first cases $[3,8]$. The origin of the first cases in Egypt were from China and Taiwan while the first cases reported in Algeria, Morocco and Tunisia were almost all from Europe (especially from Spain, France and Italy) $[7,9]$. Other cases were also reported in Tunisia and Morocco from citizens returning from Egypt. Of note, Algeria and Egypt were considered as two of the countries with the highest importation risk of COVID 19 from China while Morocco and Tunisia 
Table 1. Health system capacities of the Northern African countries (per 1000 people) [5]

\begin{tabular}{cccc}
\hline & Doctors (year) & Nurses and midwifes (year) & Hospital beds (year) \\
\hline Algeria & $1.8(2016)$ & $2.2(2016)$ & $1.9(2015)$ \\
\hline Egypt & $1.3(2017)$ & $1.4(2017)$ & $1.6(2014)$ \\
\hline Morocco & $0.8(2017)$ & $1.1(2017)$ & $1.1(2014)$ \\
\hline Tunisia & $0.7(2016)$ & $2.6(2016)$ & $2.3(2015)$ \\
\hline
\end{tabular}

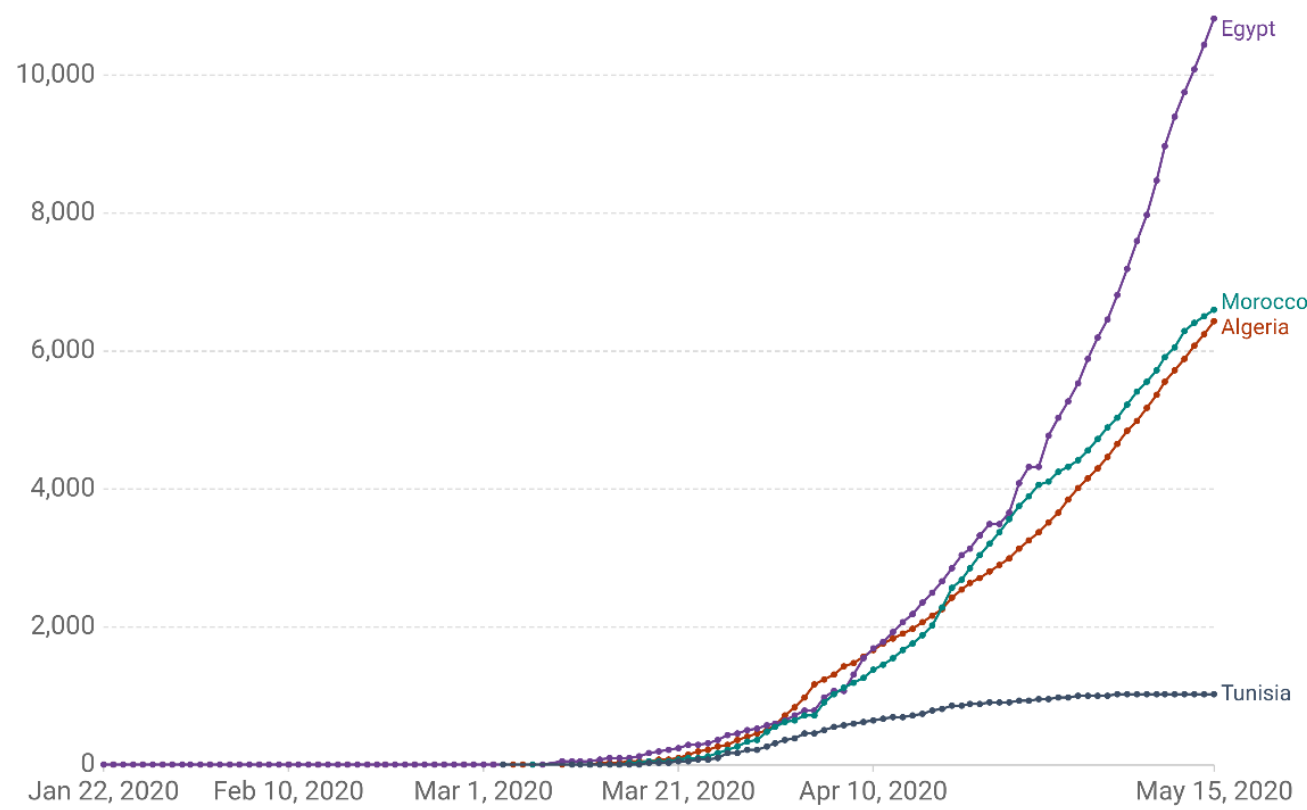

Figure 1. Cumulative number of COVID-19 cases in the Northern African countries [12]

Since the appearance of the COVID-19 the number of cases was nearly the same in Algeria, Egypt and Morocco while Tunisia recorded the lowest numbers

had a moderate and low risk respectively [6]. Furthermore, Algeria was identified as one of the thirteen nations with an especially high-risk priority zones for proactive surveillance, detection and containing the spread of this disease due to their close link with China [10].

\section{Progression and Morbidity}

Since the first appearance of the disease in the four countries, the epidemiologic curves have shown a nearly similar increase in COVID19 new cases in Algeria, Morocco and Egypt. Tunisia however recorded the lowest numbers.

In the first days, Egypt and Algeria reported the highest numbers. However, with the expansion of the number of screening tests especially in Morocco [8], the number has significantly increased, and it is occupying the second place after Egypt by May 15th, 2020 (Figure 1) $[11]$.

In the same way, Egypt has now reported 11228 positive cases, Morocco and Algeria are now with 6652 and 6629 cases respectively while Tunisia has recorded 1032 positive cases [11].

Regarding morbidity rate, Morocco has the highest rate of about (181 cases/million), followed by Algeria (about 152 cases/million) and Egypt (110 cases/ millions) while Tunisia has a rate of about (87 cases/million) [11].

This difference is however related to different factors such as the number of tests performed and the total population (see below).

\section{Laboratory Testing}

The number of tests conducted differs largely in the different countries. Even this was the weakest link in fighting this disease in the four countries, Algeria remain at the last position recording the lowest number of about 12000 tests (the median number of test was estimated of about 200 tests/day [13]) compared to Egypt $(135,000)$, Morocco (81616) and Tunisia (35623).

These numbers indicated about 3,059 tests/million inhabitant in Tunisia, 2,215/million in Morocco, 1,323/million in Egypt and a weak number that did not exceed 300 tests/million in Algeria.

\section{Mortality and Fatality Rates}

The first COVID-19 death was reported in Egypt on March 9th, while Algeria and Morocco reported their first deaths on March $11^{\text {th }}$ and $12^{\text {th }}$ respectively. The first death in Tunisia was detected about ten days later on March 22nd.

Since these first deaths, Algeria reported the highest number until May 8th when Egypt emerged with highest number (503vs 488 on May 9th) (Figure 2).

Currently (May 15th), the number of total deaths recorded is 592 in Egypt, 536 in Algeria, 190 in Morocco and 45 in Tunisia [11].

These numbers expressed different mortality rates. The higher mortality rate was observed in Algeria with a number of about 12 deaths/million followed by Egypt (6 deaths/million), Morocco (5 deaths/millions) and Tunisia (4 deaths/million) [9].

Regarding fatality rate, Algeria had the highest rate of about $8.2 \%$ followed by Egypt (5.3\%), Tunisia (4.4\%) and Morocco (2.9\%). Of note, on April 15th Algeria recorded the highest rate in the world (15.8\%) exceeding the rates reported in the most affected countries like Italy, Spain and France (9). That rate seemed however; to decrease in the last days with the increasing of the number of tests performed (Figure 3). 


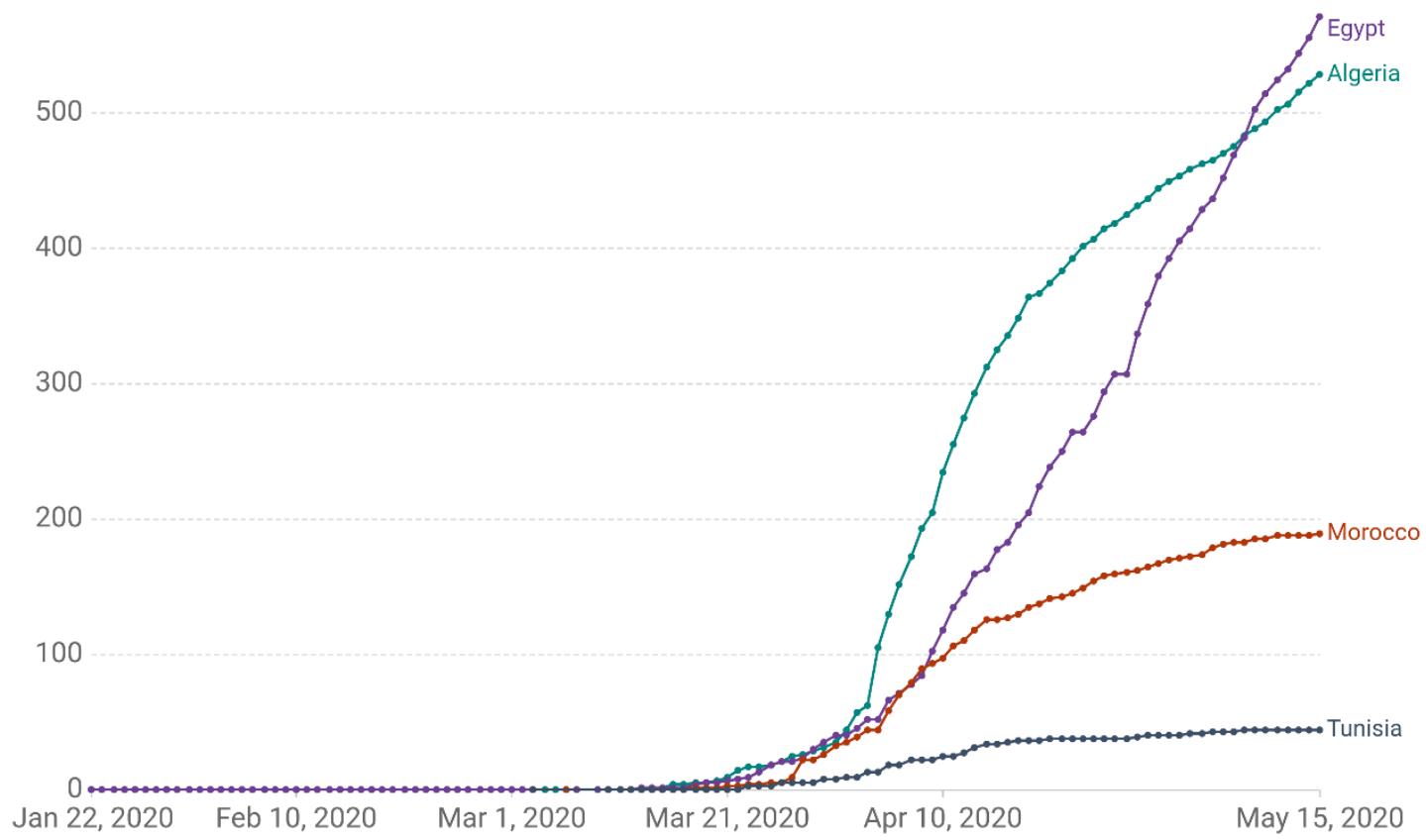

Figure 2. Cumulative number of COVID-19 deaths in the Northern African countries [12] The number of deaths was higher in Egypt and Algeria than Morocco and Tunisia

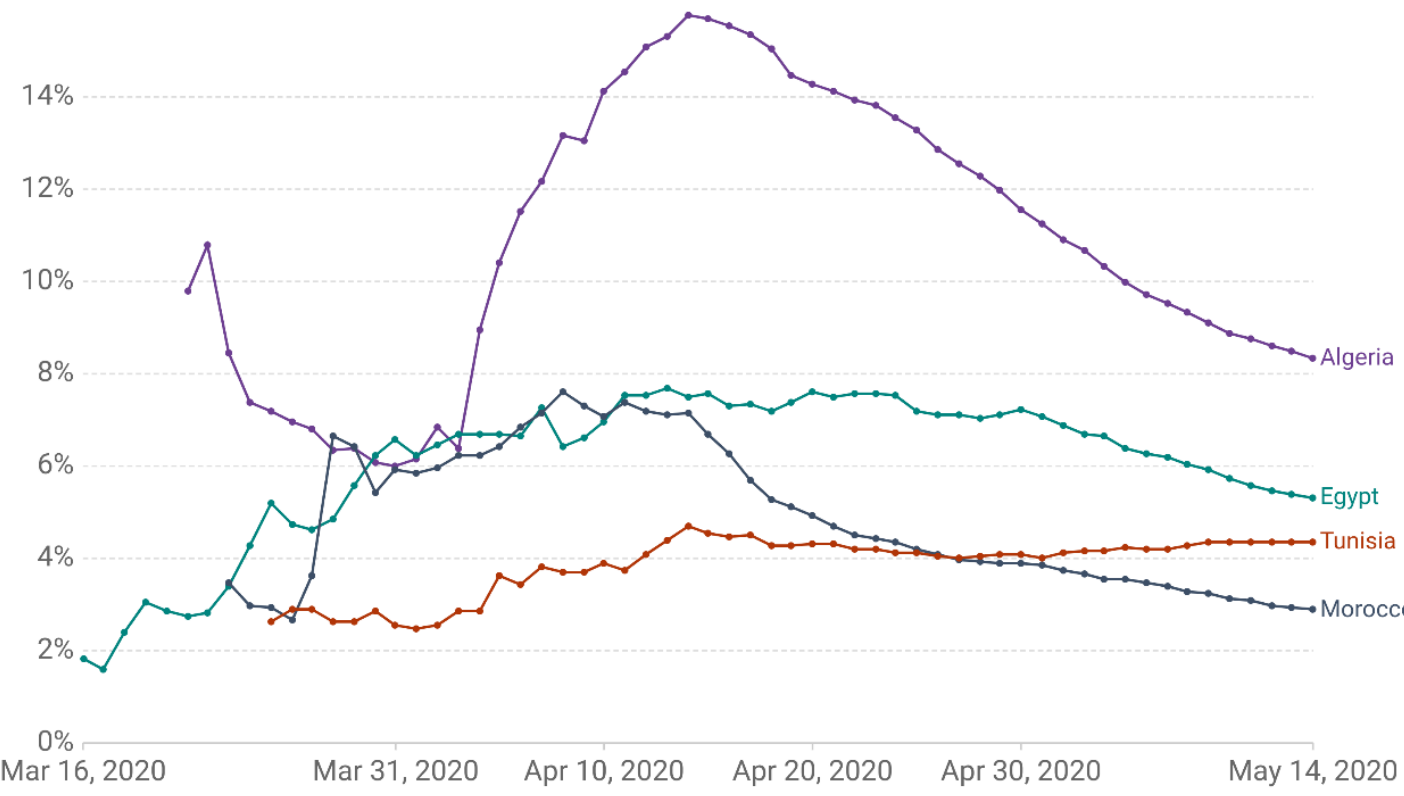

Figure 3. Case fatality rate of theCOVID-19 in the Northern African countries [12]

The case fatality rate seem to decrease in the time especially in Algeria which recorded the highest rate in the world in April 15 th, 2020

\section{Recovery}

Among the total number of positive cases, the number of recovered patients was higher in Morocco (3400) and Algeria (3271) than Egypt (2799) and Tunisia (770) (9) (Figure 2). However, the rate of recovery is highest in Tunisia (74.6\%) as compared with Morocco (51.1\%), Algeria (49.3\%) and Egypt (24.9\%).

On the other hand, recovery versus deceased ratio was the highest in Morocco (17.9) compared with Tunisia (17.1), Algeria (6.1) and Egypt (4.7).

Of notes, all the four countries are currently treating COVID-19 patients with Hydroxychloroquine protocol.

\section{Response and Containment}

After the detection of their first cases and taking into account the COVID-19 evolution in the world and especially in the countries of the Northern shore of the Mediterranean such as Italy, Spain and France, the Northern African countries have started to implement a set of measures both for the containment of the contagion (travel restrictions, gatherings restrictions) and for the mitigation of socio-economic impacts. Each country has adopted their actions according to its resources. The lack of experience from fighting epidemics by the national authorities of this region could explain the late response to COVID-19 especially in Egypt and Algeria. 
In fact, even when Egypt was the first affected North African country; its response was relatively delayed compared to the other countries. Egypt waited for more than one month from the first case report to take decisions (on March 19th) when the number was already 256 positive cases and 7 deaths and the curfew ( $7 \mathrm{pm}$ to $6 \mathrm{am}$ ) was announced on 24th of March 2020 until mid-April [9]. In the same manner, Algeria commenced a range of successive measures of travel restriction and social distancing on March 9th, but the containment was adopted on March 23th (230 cases and 17 deaths) about a month after the first reported case. A total lockdown in the epicenter of the outbreak (department of Blida) and partial containment in all the other departments were adopted [8].

Tunisia and Morocco however, reacted more quickly and more effectively by decreeing curfew (6pm-6am) (on March 18th) and a total lockdown on March 20th, 2020 (60 cases) in Tunisia (18 days after the first case) and the state of emergency and a total lockdown (March 20th) in Morocco (63 cases: 2 death deaths) [9,14].

\section{CONCLUSION}

The study showed that the Northern African countries are affected by the ongoing pandemic but efforts are on-going to control the disease. Tunisia seems to be the most efficient in the fighting against this disease since it recorded the lowest number of new cases and deaths. The other three countries have also success to delay the peak of the epidemic and consequently reduce the pressure on their health systems. This unprecedented situation may serve as a lesson. In the fighting against probable outbreaks in the future.

\section{REFERENCES}

1. Musinguzi G, Asamoah BO. The Science of Social Distancing and Total Lock Down: Does it Work? Whom does it Benefit?. Electron J Gen Med 2020;17(6):em230. (doi: 10.29333/ejgm/7895).

2. Johns Hopkins University of Medicine, Coronavirus resource center: https://coronavirus.jhu.edu/map.html (Accessed: 15 May 2020).

3. Daw MA, El-Bouzedi AH. Modeling the epidemic spread of COVID-19 virus infection in Northern African countries. Travel Med Infect Dis 2020;35:101671. (doi 10.1016/j.tmaid.2020.101671).

4. Business insider 2020. Global Health Security Index to assess the health security of 195 countries. Available at: https://www.ghs index.org/wp-content/uploads/2019/10/2019-Global-HealthSecurity-Index.pdf (Accessed: 15 May 2020).
5. Atlasocio. Available at: https://atlasocio.com/classements/sante/ infrastructures/classement-etats-par-nombre-de-lits-medicalisespour-1000-habitants-monde.php (Accessed: 15 May 2020).

6. Gilbert M, Pullano G, Pinotti G, Valdano E, Poletto C, Boëlle PY, et al. Preparedness and vulnerability of African countries against importations of COVID-19: a modeling study. Lancet 2020. 395. (doi: 10.1016/S0140-6736 (20)30411-6).

7. Lounis M. COVID-19 in Algeria: Chronology and evaluation of preventive actions. European Journal of Medical and educational Technologies 2020;13(1):em2001. (doi: 10.30935/ejmets/8012).

8. Ait Addi R, Benksim A, Amine M, Cherkaoui M. COVID-19 Outbreak and Perspective in Morocco. Electron J Gen Med. 2020;17(4):em204. (doi: 10.29333/ejgm/7857).

9. Ayadi R, Abdullah Ali S, Alshyab N, Barnieh KS Belarbi Y, Challita S, El Mekkaoui N Konya K, Ben Ayed Mouelhi R, Ramadan R, Sandri S, Shaban M, Ronco S Zaki C, Covid-19 in the Mediterranean and Africa Diagnosis, Policy Responses, Preliminary Assessment and Way Forward. Euro-Mediterranean Economists Association 2020; ISBN-13-978-84-18352-01-0, 114 p.

10. World Health Organisation: WHO ramps up preparedness for novel Coronavirus in the African region. 2020. Available at: https://www.afro.who.int/news/who-ramps-up-preparednessfor-novel-coronavirus-in-the-african-region (Accessed: 1 May 2020).

11. Coronavirus updates Live 2020. Available at: https://www. worldmeter.info/coronavirus/ (Accessed: 15 May 2020).

12. Coronavirus (COVID-19) Cases. Available at: https://ourworldin data.org/covid-cases? country=MAR+DZA+TUN+EGY

13. APS (Algerian Press Service). http://www.aps.dz/sante-sciencetechnologie/104593-covid-19-hausse-sensible-du-nombre-detests-quotidiens-dans-les-laboratoires-de-1-ipa (Accessed: 1 May 2020).

14. El Baz S, Boudjemâa I. Coronavirus disease 2019 (COVID-19): Morocco interrupting the transmission by ethics, logistic and therapeutic efforts. J Clin Experim Invest 2020;11(4):em00743. (doi: 10.5799/jcei/8214). 